ORIGINAL ARTICLE

\title{
Prolonged menstrual cycles in female workers exposed to ethylene glycol ethers in the semiconductor manufacturing industry
}

\author{
G-Y Hsieh, J-D Wang, T-J Cheng, P-C Chen
}

Occup Environ Med 2005;62:510-516. doi: 10.1136/oem.2004.016014

See end of article for authors' affiliations

Correspondence to Dr P-C Chen, Institute of Occupational Medicine and Industrial Hygiene, National Taiwan University College of Public Health, 1, Section 1, Jen-Ai Road, Taipei 100, Taiwan; pchen@ntu.edu.tw

Accepted 6 January 2005

\begin{abstract}
Background: It has been shown that female workers exposed to ethylene glycol ethers (EGEs) in the semiconductor industry have higher risks of spontaneous abortion, subfertility, and menstrual disturbances, and prolonged waiting time to pregnancy.

Aims: To examine whether EGEs or other chemicals are associated with long menstrual cycles in female workers in the semiconductor manufacturing industry.

Methods: Cross-sectional questionnaire survey during the annual health examination at a wafer manufacturing company in Taiwan in 1997. A three tiered exposure-assessment strategy was used to analyse the risk. A short menstrual cycle was defined to be a cycle less than 24 days and a long cycle to be more than 35 days.

Results: There were 606 valid questionnaires from 473 workers in fabrication jobs and 133 in nonfabrication areas. Long menstrual cycles were associated with workers in fabrication areas compared to those in non-fabrication areas. Using workers in non-fabrication areas as referents, workers in photolithography and diffusion areas had higher risks for long menstrual cycles. Workers exposed to EGEs and isopropanol, and hydrofluoric acid, isopropanol, and phosphorous compounds also showed increased risks of a long menstrual cycle.

Conclusions: Exposure to multiple chemicals, including EGEs in photolithography, might be associated with long menstrual cycles, and may play an important role in a prolonged time to pregnancy in the wafer manufacturing industry; however, the prevalence in the design, possible exposure misclassification, and chance should be considered.
\end{abstract}

ncreased risks of spontaneous abortion ${ }^{1-5}$ and subfertility ${ }^{5-7}$ have been reported among female fabrication (fab) workers in the semiconductor industry. Furthermore, a prolonged time to pregnancy occurred among female workers who were exposed to ethylene glycol ethers (EGEs) in the semiconductor manufacturing industry. ${ }^{7}$ Animal studies and human culture cells have suggested that the major metabolite of ethylene glycol monomethyl ether, 2-methoxyacetic acid, is most significantly associated with the increase of these risks. ${ }^{8-11}$

Few studies ${ }^{12}{ }^{13}$ have discussed the relation between occupational exposure to contaminants and a change in menstrual cycles. A prospective semiconductor industry study ${ }^{12}$ found that the mean and standard deviation of the cycle length were significantly greater among female workers engaged in thin film and ion implantation jobs than among non-fabrication (non-fab) workers. They reported a higher risk of short menstrual cycles among supervising engineers and photolithography workers than with non-fab workers; however, no significant difference was observed between the exposed workers who handle 2-ethoxyethylacetate in the liquid crystal display manufacturing industry and referent groups for the duration of each menstrual cycle, duration of menses, and the amount of flow. ${ }^{13}$

In this study, we examined the determinants of menstrual cycle variations for 606 female workers with and without occupational exposure to chemicals, including EGEs, in a wafer manufacturing company. In particular, we examined whether EGEs or other chemicals were associated with having experienced long menstrual cycles, which may help explain and buttress our previous finding of prolonged time to pregnancy. ${ }^{7}$

\section{METHODS}

\section{Study population}

This wafer manufacturing company was established in March 1990 to produce dynamic random access memory (DRAM) chips. The process involves many repeated cycles of thin film, photolithography, diffusion, and etching. We conducted this study during the annual health examination for all 842 female employees of the company located in Taiwan during 1997, as shown in fig 1. Our time-topregnancy study ${ }^{7}$ has already been conducted within this cohort. A total of 719 female workers completed the questionnaires with a response rate of $85.4 \%$. One hundred and thirteen subjects were excluded because of potentially large measurement errors or biases: 49 workers who could not remember pertinent data correctly or were excluded due to pregnancy or menopause, 11 workers who used contraceptive practices, 19 workers who physically entered the plant for less than one year or worked in more than one area in the past year, and 30 workers in testing areas and four workers in the storage room environments. A total of 606 female workers were included in the subsequent analysis; they were pre-menopausal women aged 18-40 who were not pregnant or breast feeding, had not used oral contraceptives in the preceding year, did have menstruation cycles during that year, and did not have a treatment history for menstrual irregularity and infertility, pelvic inflammatory diseases, endometriosis, and/or major abdominal surgery. All study

Abbreviations: $\mathrm{BMI}$, body mass index; $\mathrm{Cl}$, confidence interval; DRAM, dynamic random access memory; EGEs, ethylene glycol ethers; Fab, fabrication; HF, hydrofluoric acid; IPA, isopropyl alcohol, isopropanol; Non-fab, non-fabrication; OR, odds ratio 


\section{Main messages}

- Exposure to multiple chemicals, including ethylene glycol ethers in photolithography, might be associated with prolonged menstrual cycles in female workers. This may play an important role in prolonged time to pregnancy in female workers of wafer manufacturing

participants provided informed consent previously as approved by the Ethic Review Board of the National Taiwan University College of Public Health.

\section{Exposure assessment}

Following Hammond and colleagues, ${ }^{14}$ a three tiered exposure assessment strategy was used in the study (non-fab versus fab workers, work areas, and chemical exposure groups), as shown in fig 1 . We first conducted a hazard recognition assessment in each department of the factory and compiled a chemical inventory check list for the different work areas and unit operations. The first tier classified workers into non-fab and fab groups. The latter group was further classified within the second tier by their location: etching, thin film, photolithography, and diffusion work areas. The third tier was comprised of multiple chemical exposure groups. Evaluations were based on the workers' questionnaires regarding unit operations and work tasks performed, and were verified by industrial hygienists during site visits. Exposure information was

\section{Policy implications}

- Ethylene glycol ether should not be used in fabrication of wafer and the potential health effect of isopropyl alcohol should be re-evaluated.

obtained without prior knowledge of menstrual cycle characteristics.

\section{The questionnaire}

We provided a structured questionnaire for each subject to complete a week before the health examination. We employed three female interviewers who were mutually standardised (three times) to conduct the interview and verified the content of each item in an isolated area during the collection of questionnaires. Information on women's demographic and potential risk factors related to menstrual cycle characteristics was also requested, as shown in table 1. A psychosocial score (based on the Chinese Health Questionnaire ${ }^{15}$ ) was determined for each worker and then classified into low (0), middle (1-3), and high (4+) stress levels. Moreover, work patterns were categorised into three groups: weekday work ( $8 \mathrm{am}-6 \mathrm{pm})$, day shift ( $7 \mathrm{am}-7 \mathrm{pm})$, and night shift (7 pm-7 am). Questions relating to menstruation were included as part of a reproductive history. We assessed six menstrual characteristics for the past year (length of cycles, variability in the length of cycles, duration of bleeding, amount of flow, premenstrual changes in

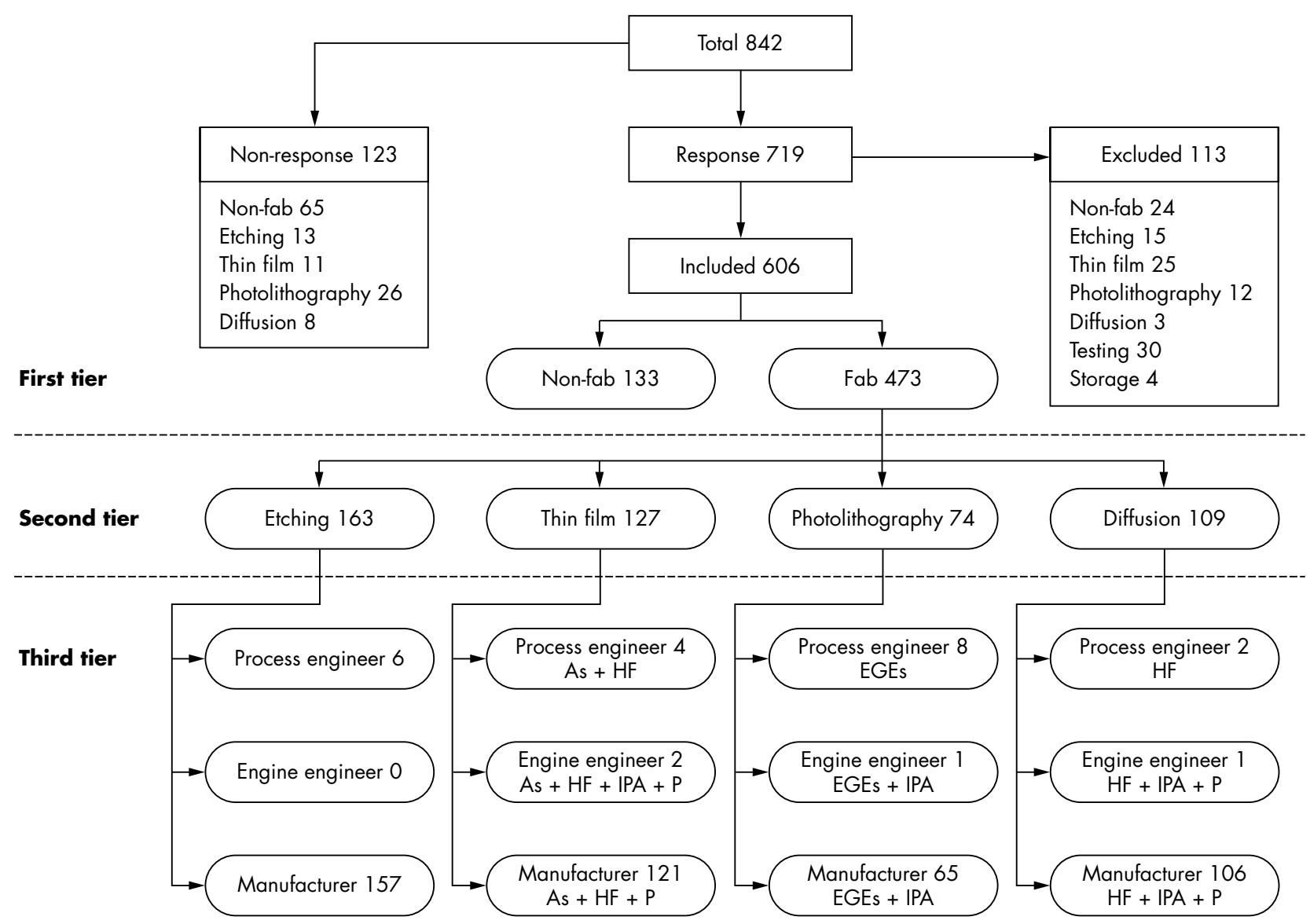

Figure 1 The study population and three tiered exposure assessment. As, arsenic compounds; EGEs, ethylene glycol ethers; fab, fabrication; HF, hydrofluoric acid; IPA, isopropyl alcohol; non-fab, non-fabrication; P, phosphorous compounds. 
Table 1 Frequency distributions of demographic and life style characteristics in female workers by non-fabrication (non-fab) and fabrication (fab) work areas

\begin{tabular}{|c|c|c|c|c|c|}
\hline \multirow[b]{2}{*}{ Demographic and lifestyle characteristics } & \multirow[b]{2}{*}{ Non-fab } & \multicolumn{4}{|l|}{ Fab } \\
\hline & & Etching & Thin film & Photolithography & Diffusion \\
\hline $\begin{array}{l}\text { Number of workers } \\
\text { Age (\%) }\end{array}$ & 133 & 163 & 127 & 74 & 109 \\
\hline$<23$ years & 9.8 & 28.8 & 44.1 & 28.4 & 38.5 \\
\hline $23-29$ years & 48.1 & 44.2 & 36.2 & 39.2 & 41.3 \\
\hline$>29$ years & 42.1 & 27.0 & 19.7 & 32.4 & 20.2 \\
\hline \multicolumn{6}{|l|}{ Education (\%) } \\
\hline High school & 44.4 & 86.5 & 79.5 & 85.1 & 96.3 \\
\hline College/university & 55.6 & 13.5 & 20.5 & 14.9 & 3.7 \\
\hline \multicolumn{6}{|l|}{ Current smoking (\%) } \\
\hline No & 99.2 & 96.3 & 92.1 & 95.9 & 94.5 \\
\hline Yes & 0.8 & 3.7 & 7.9 & 4.1 & 5.5 \\
\hline \multicolumn{6}{|l|}{ Current drinking (\%) } \\
\hline No & 65.4 & 62.6 & 64.6 & 67.6 & 65.1 \\
\hline Yes & 34.6 & 37.4 & 35.4 & 32.4 & 34.9 \\
\hline \multicolumn{6}{|l|}{ Current coffee (\%) } \\
\hline No & 33.8 & 38.0 & 41.7 & 50.0 & 42.2 \\
\hline Yes & 66.2 & 62.0 & 58.3 & 50.0 & 57.8 \\
\hline \multicolumn{6}{|l|}{ Current tea (\%) } \\
\hline No & 15.0 & 18.4 & 11.8 & 27.0 & 16.5 \\
\hline Yes & 85.0 & 81.6 & 88.2 & 73.0 & 83.5 \\
\hline \multicolumn{6}{|l|}{ Extra work (\%) } \\
\hline No & 73.7 & 61.3 & 45.7 & 45.9 & 64.2 \\
\hline Yes & 26.3 & 38.7 & 54.3 & 54.1 & 35.8 \\
\hline \multicolumn{6}{|l|}{ Work pattern (\%) } \\
\hline Weekday work (8 am-6 pm) & 53.4 & 5.5 & 5.5 & 12.2 & 3.7 \\
\hline Day work $(7 \mathrm{am}-7 \mathrm{pm})$ & 42.9 & 64.4 & 36.2 & 47.3 & 24.8 \\
\hline Night work (7 pm-7 am) & 3.8 & 30.1 & 58.3 & 40.5 & 71.6 \\
\hline \multicolumn{6}{|l|}{ Stress level classified by psychiatric score (\%) } \\
\hline Low & 54.1 & 41.7 & 44.9 & 40.5 & 38.5 \\
\hline Medium & 31.6 & 41.7 & 39.4 & 40.5 & 43.1 \\
\hline High & 14.3 & 16.6 & 15.7 & 18.9 & 18.3 \\
\hline \multicolumn{6}{|l|}{ Body mass index (\%) } \\
\hline$<19 \mathrm{~kg} / \mathrm{m}^{2}$ & 27.8 & 28.2 & 29.1 & 31.1 & 27.5 \\
\hline $19-24 \mathrm{~kg} / \mathrm{m}^{2}$ & 59.4 & 56.4 & 57.5 & 52.7 & 65.1 \\
\hline$>24 \mathrm{~kg} / \mathrm{m}^{2}$ & 12.8 & 15.3 & 13.4 & 16.2 & 7.3 \\
\hline \multicolumn{6}{|l|}{ Pregnancy history (\%) } \\
\hline No & 57.1 & 56.4 & 71.7 & 58.1 & 66.1 \\
\hline Yes & 42.9 & 43.6 & 28.3 & 41.9 & 33.9 \\
\hline
\end{tabular}

physiological function, and premenstrual changes in mental function), with discrete categorical response options.

To classify menstrual cycle length, we asked women: "In the past year, on average, how long have your cycles been?" To measure the probability of extreme cycle lengths, the percentages of women who had short ( $<24$ days) or long (>35 days) cycles were computed. Cut-offs at 24 and 35 days were selected based on prospective studies ${ }^{16-18}$ showing that $10 \%$ of all cycles in pre-menopausal women were $<24$ days, and $10 \%$ were $>35$ days. To evaluate the variability of cycle length, we asked women: "In the past year, how many days were your cycles different from an average cycle length (that is, the number of days from the start of one period to the start of the next was about the same and if different, how many days)?". To measure the regularity of menstrual cycles, we classified those with a difference of seven days or more as having irregular cycles. To measure the duration of bleeding, we asked women: "In the past year, on average, how many days did your flow last?". We classified those with less than three days or more than six days of flow as abnormal. To assess the amount of flow, we asked women: "During the past year, on average, how many sanitary towels did you use every day during menses?". We classified the use of more than eight to be abnormal.

The premenstrual syndrome ${ }^{19} 20$ is a combination of mental and physical symptoms arising in the luteal phase of the menstrual cycle. The mental syndrome included the following 11 symptoms: mood liability, anxiety, tension, depression, lethargy, fatigue, mood swings, aggressiveness, feelings of insecurity, confusion, and a craving for sweet food. More than four symptoms was defined as abnormal. The physical syndrome included abdominal bloating, abdominal discomfort or pain, breast tenderness or pain, weight gain, oedema, headaches, backaches, and/or nausea. Again, the exhibition of more than four symptoms was defined as abnormal.

\section{Statistical analysis}

$\chi^{2}$ tests were applied to compare the menstrual characteristics and cycles of female workers among the fab versus nonfab groups and in the different work areas. A logistic regression was used to estimate crude and odds ratios (ORs) with 95\% confidence intervals (CIs) of the menstrual cycles according to fab, work areas, and chemical exposure groups with the exception of small samples. The reference group was comprised of female workers who were either in the non-fab group or in the etching area of the fab group, where there was no exposure to EGEs, isopropyl alcohol (IPA), arsenic compounds, phosphorous compounds, and hydrofluoric acid (HF). In the multivariable models, we used a change-in-estimate criterion to identify confounding variables. The following set of variables was included in all final models: age, current smoking habits, work patterns, extra work, stress level classified by a psychiatric score, body mass index (BMI), and pregnancy history. Education was also controlled for because it may be a proxy for health level and also for reporting of menstrual cycle characteristics.

We noted that prevalence ORs tend to overestimate the relative risk. ${ }^{21}$ Since the prevalence for long menstrual cycles 
Table 2 Frequency distributions of menstrual cycle characteristics in female workers by non-fabrication (non-fab) and fabrication (fab) work areas

\begin{tabular}{|c|c|c|c|c|c|}
\hline \multirow[b]{2}{*}{ Menstruation cycle characteristics } & \multirow[b]{2}{*}{ Non-fab } & \multicolumn{4}{|l|}{ Fab } \\
\hline & & Etching & Thin film & Photolithography & Diffusion \\
\hline \multicolumn{6}{|l|}{ Length of cycle (\%) } \\
\hline$<24$ days & 4.5 & 6.7 & 5.5 & 8.1 & 5.5 \\
\hline $24-35$ days & 84.2 & 82.8 & 77.2 & 64.9 & 71.6 \\
\hline$>35$ days & 11.3 & 10.4 & 17.3 & 27.0 & 22.9 \\
\hline \multicolumn{6}{|l|}{ Variability in length of cycle (\%) } \\
\hline$<7$ days & 84.2 & 90.8 & 84.3 & 75.7 & 80.7 \\
\hline$\geqslant 7$ days & 15.8 & 9.2 & 15.7 & 24.3 & 19.3 \\
\hline \multicolumn{6}{|l|}{ Duration of bleeding (\%) } \\
\hline $3-6$ days & 76.7 & 76.7 & 75.6 & 79.7 & 78.9 \\
\hline$<3$ or $>6$ days & 23.3 & 23.3 & 24.4 & 20.3 & 21.1 \\
\hline \multicolumn{6}{|l|}{ Amount of flow (\%) } \\
\hline$\leqslant 8$ sanitary towels & 77.4 & 79.8 & 82.7 & 85.1 & 82.6 \\
\hline$>8$ sanitary towels & 22.6 & 20.2 & 17.3 & 14.9 & 17.4 \\
\hline \multicolumn{6}{|l|}{ Premenstrual mental symptoms* (\%) } \\
\hline $0-3$ & 83.5 & 84.0 & 85.0 & 83.8 & 85.3 \\
\hline$\geqslant 4$ & 16.5 & 16.0 & 15.0 & 16.2 & 17.4 \\
\hline \multicolumn{6}{|l|}{ Premenstrual physical symptoms† (\%) } \\
\hline $0-3$ & 85.0 & 89.6 & 83.5 & 86.5 & 78.9 \\
\hline$\geqslant 4$ & 15.0 & 10.4 & 16.5 & 13.5 & 22.0 \\
\hline
\end{tabular}

*Mental premenstrual symptoms include mood liability, anxiety, tension, depression, lethargy, fatigue, mood swings, aggressiveness, feelings of insecurity, confusion, and a craving for sweet food. Subjects exhibiting four or more symptoms were defined as abnormal.

†Physical premenstrual symptoms include abdominal bloating, abdominal discomfort or pain, breast tenderness or pain, weight gain, oedema, headaches, backaches, and nausea. Subjects exhibiting four or more symptoms were defined as abnormal.

in different work areas ranged from $10 \%$ to $30 \%$, the OR may not be a good approximation of the prevalence ratios. Nevertheless, the use of prevalence ORs enabled us to compare the crude prevalence ORs with the adjusted ORs in the logistic regression model.

\section{RESULTS}

There were 606 valid questionnaires in which 133 women workers in non-fab jobs and 473 in fab were analysed in this study. Of the female workers in non-fab and fab groups, the ages of workers in the non-fab group were slightly older than in the fab group, workers in photolithography were older than those in other work areas, and non-fab workers' education levels were generally higher (more than $50 \%$ of them graduated from college or university), as detailed in table 1 . The work pattern in almost all non-fab workers was on either a weekday or day shift basis; fab workers work for either day or night shifts. More than $40 \%$ of female workers in the non-fab, etching, and photolithography areas had conceived before this study.

Menstrual characteristics, except the average length of cycle, showed no difference between non-fab and fab female workers. There was no difference in frequencies of short menstrual cycles between non-fab and fab workers or by work areas, as shown in table 2. However, there were major differences for long menstrual cycles between non-fab and fab workers or work areas including the thin film, photolithography, and diffusion areas. Long menstrual cycles also correlated closely with seven days or more of variability in length of their cycles (data not shown).

Table 3 shows crude ORs and 95\% CIs for short and long menstrual cycles in female workers according to work areas, potential exposure to chemical agents, and demographic and lifestyle characteristics. There was no significant finding for short menstrual cycles, but there were higher odds ratios for long menstrual cycles in female workers of fab and work areas, including photolithography and diffusion areas, based on analyses of workers in nonfab as referents, as shown in table 3. Workers exposed to EGEs and IPA (OR 3.3; 95\% CI 1.5 to 7.1 ) and hydrofluoric acid, IPA, and phosphorous compounds (OR 2.3; 95\% CI 1.1 to 4.7) also showed increased risks of a long menstrual cycle.

After adjustment for potential confounders, multivariable models showed that the association between long menstrual cycle and multiple chemicals compared with non-fab workers was strong for EGEs and IPA (OR 5.0; 95\% CI 1.7 to 14.1), and hydrofluoric acid, IPA, and phosphorous compounds (OR 3.5; 95\% CI 1.1 to 10.9), with little evidence for arsenic compounds, hydrofluoric acid, and phosphorous compounds (OR 2.0; 95\% CI 0.8 to 5.5). When compared with those in the etching area, these associations still existed, as shown in table 4 .

\section{DISCUSSION}

We found that exposure to multiple chemicals, particularly including EGEs or IPA, was associated with female fab workers with long menstrual cycles. Because there were wide differences between fab and non-fab workers with respect to age, education, smoking, extra work, and work patterns, we used workers in both non-fab and etching areas as dual reference groups (table 4), which consistently showed such an association and corroborated the above hypothesis. Although it does not necessarily follow that they are causally related, the following discussion suggests that such a causal link may exist.

Firstly, all workers were required by law to participate in an annual health examination with a response rate of $85.4 \%$ that was relatively high in the study. Thus, the likelihood of selection bias was low. Secondly, women may be exposed concurrently to multiple agents, and one agent may be used in multiple work areas. For this reason, it was difficult to evaluate the level of each exposure for every worker; this might introduce non-differential misclassification of exposure and result in bias towards the null. Thirdly, there was no prior report about any association between long menstrual cycles and specific exposure among fab workers, and thus no inclination for reporting bias. Fourthly, because random misclassification generally leads towards the null, the increased random error in menstruation histories under a retrospective design cannot explain the positive association. 
Table 3 Crude odds ratios and $95 \%$ confidence intervals for short and long menstrual cycles in female workers according to work areas, potentially exposed chemical agents, and demographic and lifestyle characteristics

\begin{tabular}{|c|c|c|c|c|c|}
\hline \multirow[b]{2}{*}{ Risk factors } & \multicolumn{3}{|c|}{ Number of workers } & \multirow[b]{2}{*}{$\begin{array}{l}\text { Crude OR }(95 \% \mathrm{Cl}) \text { for } \\
\text { short menstrual cycles }\end{array}$} & \multirow[b]{2}{*}{$\begin{array}{l}\text { Crude OR }(95 \% \mathrm{Cl}) \text { for } \\
\text { long menstrual cycles }\end{array}$} \\
\hline & $\begin{array}{l}\text { Short range } \\
<24 \text { days }\end{array}$ & $\begin{array}{l}\text { Normal range } \\
24-35 \text { days }\end{array}$ & $\begin{array}{l}\text { Long range } \\
>35 \text { days }\end{array}$ & & \\
\hline Non-fab & 6 & 112 & 15 & 1 & 1 \\
\hline $\mathrm{Fab}$ & 30 & 359 & 84 & 1.6 (0.6 to 3.8 ) & $1.8(1.0$ to 3.1$)$ \\
\hline Etching & 11 & 135 & 17 & 1.5 (0.6 to 4.2$)$ & $0.9(0.5$ to 2.0$)$ \\
\hline Thin film & 7 & 98 & 22 & $1.3(0.4$ to 4.1$)$ & $1.7(0.8$ to 3.4$)$ \\
\hline $\mathrm{As}+\mathrm{HF}$ & - & 3 & 1 & - & - \\
\hline $\mathrm{As}+\mathrm{HF}+\mathrm{P}$ & 7 & 93 & 21 & $1.4(0.5$ to 4.3$)$ & $1.7(0.8$ to 3.5$)$ \\
\hline$A s+H F+I P A+P$ & - & 2 & - & - & - \\
\hline Photolithography & 6 & 48 & 20 & $2.3(0.7$ to 7.6$)$ & $3.1(1.5$ to 6.6$)$ \\
\hline EGEs & 2 & 5 & 1 & - & - \\
\hline EGEs+IPA & 4 & 43 & 19 & $1.7(0.5$ to 6.5$)$ & $3.3(1.5$ to 7.1$)$ \\
\hline Diffusion & 6 & 78 & 25 & $1.4(0.5$ to 4.6$)$ & $2.4(1.2$ to 4.8$)$ \\
\hline $\mathrm{HF}$ & - & 1 & 1 & - & - \\
\hline \multirow{2}{*}{\multicolumn{6}{|c|}{ Age }} \\
\hline & & & & & \\
\hline $23-29$ years & 15 & 190 & 51 & 1 & 1 \\
\hline$<23$ years & 11 & 149 & 19 & $0.9(0.4$ to 2.1$)$ & $0.5(0.3$ to 0.8$)$ \\
\hline$>29$ years & 10 & 132 & 29 & 1.0 (0.4 to 2.2$)$ & $0.8(0.5$ to 1.4$)$ \\
\hline \multicolumn{6}{|l|}{ Education } \\
\hline High school & 28 & 361 & 80 & 1 & 1 \\
\hline College/university & 8 & 110 & 19 & $0.9(0.4$ to 2.1$)$ & $0.8(0.5$ to 1.3$)$ \\
\hline \multicolumn{6}{|l|}{ Current smoking } \\
\hline No & 35 & 452 & 93 & 1 & 1 \\
\hline Yes & 1 & 19 & 6 & 0.7 (0.1 to 5.2$)$ & $1.5(0.6$ to 3.9$)$ \\
\hline \multicolumn{6}{|l|}{ Current drinking } \\
\hline No & 22 & 305 & 65 & 1 & 1 \\
\hline Yes & 14 & 166 & 34 & $1.2(0.6$ to 2.3$)$ & $1.0(0.6$ to 1.5$)$ \\
\hline \multicolumn{6}{|l|}{ Current coffee } \\
\hline No & 15 & 185 & 43 & 1 & 1 \\
\hline Yes & 21 & 286 & 56 & $0.9(0.5$ to 1.8$)$ & 0.8 (0.5 to 1.3$)$ \\
\hline \multicolumn{6}{|l|}{ Current tea } \\
\hline No & 9 & 76 & 18 & 1 & 1 \\
\hline Yes & 27 & 395 & 81 & 0.6 (0.3 to 1.3 ) & 0.9 (0.5 to 1.5$)$ \\
\hline \multicolumn{6}{|l|}{ Often extra work } \\
\hline No & 19 & 281 & 60 & 1 & 1 \\
\hline Yes & 17 & 190 & 39 & $1.3(0.7$ to 2.6$)$ & $1.0(0.6$ to 1.5$)$ \\
\hline \multicolumn{6}{|l|}{ Work pattern } \\
\hline Weekday work (8 am-6 pm) & 5 & 82 & 13 & 1 & 1 \\
\hline Day work (7 am-7 pm) & 16 & 202 & 52 & $1.3(0.5$ to 3.7$)$ & $1.6(0.8$ to 3.1$)$ \\
\hline Night work (7 pm-7 am) & 15 & 187 & 34 & $1.3(0.5$ to 3.7$)$ & $1.2(0.6$ to 2.3$)$ \\
\hline \multicolumn{6}{|c|}{ Stress level classified by psychiatric score } \\
\hline Low & 12 & 221 & 221 & 1 & 1 \\
\hline Medium & 18 & 180 & 180 & $1.8(0.9$ to 3.9$)$ & $1.3(0.8$ to 2.2$)$ \\
\hline High & 6 & 70 & 70 & $1.6(0.6$ to 4.4$)$ & $2.1(1.2$ to 3.8$)$ \\
\hline \multicolumn{6}{|l|}{ Body mass index } \\
\hline $19-24 \mathrm{~kg} / \mathrm{m}^{2}$ & 19 & 273 & 62 & 1 & 1 \\
\hline$<19 \mathrm{~kg} / \mathrm{m}^{2}$ & 13 & 138 & 22 & $1.4(0.7$ to 2.8$)$ & 0.7 (0.4 to 1.2$)$ \\
\hline$>24 \mathrm{~kg} / \mathrm{m}^{2}$ & 4 & 60 & 15 & $1.0(0.3$ to 2.9$)$ & $1.1(0.6$ to 2.1$)$ \\
\hline \multicolumn{6}{|l|}{ Pregnancy history } \\
\hline No & 24 & 292 & 58 & 1 & 1 \\
\hline Yes & 12 & 179 & 41 & $0.8(0.4$ to 1.7$)$ & $1.2(0.7$ to 1.8$)$ \\
\hline
\end{tabular}

Fifthly, potential confounders including age, education, high BMI (overweight), ${ }^{22}{ }^{23}$ stress, $^{22}$ smoking, ${ }^{23} 24$ night work, ${ }^{25}$ often extra work, and pregnancy histories were controlled for in multivariable models. However, we did not control for physical activity ${ }^{22}{ }^{26}$ because of the small proportion of premenopausal women with moderate or high levels of regular exercise in Taiwan. Although the majority of jobs in the nonfab areas were sedentary, there were similar levels of physical labour among female workers in fab work areas. These risk factors did not explain the association found between long menstrual cycles and exposure in photolithography and diffusion work areas. Finally, our previous study also found a prolonged time to pregnancy in fab workers exposed to EGEs, other than in the etching operation area. Therefore, we tentatively concluded that an association exists for multiple chemical exposure including EGEs. Clearly, we should also look for an additional causal hypothesis for workers unexposed to EGEs.
Animal studies have shown that the major metabolite of ethylene glycol monomethyl ether, 2-methoxyacetic acid, penetrates the placenta of non-human primates. ${ }^{8}{ }^{9}$ This metabolite altered the ovarian luteal function, and increased ovarian luteal cell progesterone production in female rats ${ }^{10}$ and in cultured human cells. ${ }^{11}$ Previous epidemiological studies suggested that long cycles may indicate delayed ovulation, ${ }^{27}$ and short cycles may reflect a short follicular phase ${ }^{28}$ or anovulation. ${ }^{29}$ Exposure to EGEs was associated with prolonged time to pregnancy in female fab workers. ${ }^{7}$ Therefore, we concluded that prolonged menstrual cycles in female workers exposed to EGEs might be associated with their prolonged time to pregnancy.

The diffusion operation was found to have an increased risk for a long menstrual cycle after adjustment for other risk factors and involves exposure to hydrofluoric acid, IPA, and phosphorous compounds. Since the combined exposure of hydrofluoric acid, phosphorous compounds, and arsenic 
Table 4 Adjusted odds ratios and $95 \%$ confidence intervals for short and long menstrual cycles in female workers according to work areas and potentially exposed chemical agents

\begin{tabular}{|c|c|c|c|c|}
\hline \multirow[b]{2}{*}{ Risk factors } & \multicolumn{2}{|l|}{ Compared with non-fab } & \multicolumn{2}{|l|}{ Compared with etching } \\
\hline & $\begin{array}{l}\text { Adjusted OR* }(95 \% \mathrm{Cl}) \text { for } \\
\text { short menstrual cycles }\end{array}$ & $\begin{array}{l}\text { Adjusted } \mathrm{OR}^{*}(95 \% \mathrm{Cl}) \text { for } \\
\text { long menstrual cycles }\end{array}$ & $\begin{array}{l}\text { Adjusted OR* }(95 \% \mathrm{Cl}) \text { for } \\
\text { short menstrual cycles }\end{array}$ & $\begin{array}{l}\text { Adjusted } \mathrm{OR}^{*}(95 \% \mathrm{Cl}) \text { for } \\
\text { long menstrual cycles }\end{array}$ \\
\hline Non-fab & 1 & 1 & & \\
\hline $\mathrm{Fab}$ & $1.5(0.5$ to 4.7$)$ & $2.0(1.0$ to 3.9$)$ & & \\
\hline Etching & $1.4(0.4$ to 4.7$)$ & 0.9 (0.4 to 2.2$)$ & 1 & 1 \\
\hline Thin film & $1.4(0.3$ to 5.8$)$ & $2.0(0.8$ to 4.9$)$ & $0.9(0.3$ to 2.5$)$ & $2.2(1.1$ to 4.8$)$ \\
\hline $\mathrm{As}+\mathrm{HF}+\mathrm{P}$ & $1.6(0.3$ to 7.2$)$ & $2.0(0.8$ to 5.5$)$ & $0.9(0.3$ to 2.5$)$ & 2.1 (1.0 to 4.5$)$ \\
\hline Photolithography & $1.6(0.3$ to 9.4$)$ & $4.4(1.7$ to 11.4$)$ & $1.3(0.4$ to 4.0$)$ & $4.5(2.0$ to 10.0$)$ \\
\hline EGEs+IPA & $0.3(0.0$ to 3.7$)$ & $5.0(1.7$ to 14.1$)$ & $0.9(0.3$ to 3.2$)$ & $4.4(2.0$ to 10.0$)$ \\
\hline Diffusion & $1.3(0.2$ to 8.6$)$ & $3.8(1.3$ to 11.6$)$ & $1.2(0.4$ to 4.0$)$ & $4.1(1.8$ to 9.4$)$ \\
\hline $\mathrm{HF}+\mathrm{IPA}+\mathrm{P}$ & $1.5(0.2$ to 10.2$)$ & $3.5(1.1$ to 10.9$)$ & $1.2(0.4$ to 4.0$)$ & $3.9(1.7$ to 9.1$)$ \\
\hline
\end{tabular}

As, arsenic compounds; EGEs, ethylene glycol ethers; fab, fabrication; HF, hydrofluoric acid; IPA, isopropyl alcohol; non-fab, non-fabrication; P, phosphorous compounds.

*Adjusted for age, education, current smoking habits, work pattern, extra work, stress level classified by psychiatric score, body mass index, and pregnancy history.

compounds at thin film operation did not show a similar risk, we suspected that IPA might be the major risk factor from Mill's method of difference. ${ }^{30}$ Moreover, workers usually moved around several work areas. Further, there was a strong ventilation system in the fab areas. One might suspect that there was increased likelihood for exposure misclassification. Nonetheless, we still detected long menstruation cycles in the diffusion and photolithography areas, in which the former did not involve exposure to EGEs. The fact corroborated with the IPA hypothesis. Although an endocrine or menstrual disturbance has not been reported, IPA was found to be an embryotoxic agent in rats ${ }^{31}$ and could be a potentially toxic chemical to menstruation. The chemical properties of IPA are similar to those of ethyl alcohol, which has been shown to increase oestradiol levels during the early follicular phase, suppress FSH and preovulatory follicular growth, and prolong the follicular phase. ${ }^{32}{ }^{33}$ Therefore, future studies on the possible effect by IPA on menstrual cycle length are warranted.

This prevalence study may suffer from a survival bias inherent to such studies. Menstrual cycle characteristics were assessed using questionnaires as part of their annual health examination. Female workers with ailments were likely to miss the annual health examination or to quit their jobs. The outcome was thus underestimated due to a healthy worker effect. Conversely, female workers quit their jobs because of pregnancy and those who were infertile remained at work. This infertile worker effect ${ }^{34}$ would affect the outcome in the other direction. Altogether, it would seem that no obvious selection bias existed in this study.

A potential limitation of this study is that menstrual cycle characteristics may not be a sensitive indicator of changes or disturbances in hormonal function resulting from occupational and environmental exposure. ${ }^{35}$ Changes in ovarian function, including a short luteal phase, luteal phase insufficiency, or anovulation, cannot be accurately detected without daily measurements of reproductive hormones or their metabolites during each cycle. ${ }^{36}$ Nevertheless, selfreporting recall of menstrual cycle characteristics still provides reasonably accurate estimates when prospective studies are not practical or feasible. ${ }^{37}$

Gold and colleagues ${ }^{12}$ used daily diaries to obtain data on menstrual characteristics, a more reliable and valid method, and found that women working in photolithography were more likely to have cycles of less than 24 days (adjusted relative risk 1.8 ; $95 \%$ CI 0.9 to 2.9 ) compared to non-fab workers; this appears to be in contrast to our finding that women in photolithography were more likely to have cycles longer than 35 days. The Gold et al study was prospectively designed for investigating spontaneous abortion, and women who had not menstruated within the past two months were excluded. Thus, women likely to have had long or irregular cycles were likely to have been excluded.

In conclusion, exposure to multiple chemicals including EGEs in photolithography might be associated with long menstrual cycles and may play an important role in a prolonged time to pregnancy in the wafer manufacturing industry. IPA findings were also associated with long menstrual cycles and deserve future studies. However, the prevalence in the design, possible exposure misclassification, and chance should be considered.

\section{ACKNOWLEDGEMENTS}

We thank Marc B Schenker for helpful comments during the initiation of this study.

\section{Authors' affiliations}

G-Y Hsieh, J-D Wang, T-J Cheng, P-C Chen, Institute of Occupational Medicine and Industrial Hygiene, National Taiwan University College of Public Health, Taipei, Taiwan

Funding: this study was supported by grants from the National Health Research Institute (DOH86-HR-504 and DOH87-HR-504) and National Science Council (NSC89-2320-B-002-126), Taiwan

Competing interests: none

\section{REFERENCES}

1 Pastides H, Calabrese EJ, Hosmer DW Jr, et al. Spontaneous abortion and general illness symptoms among semiconductor manufacturers. J Occup Med 1988;30:543-51

2 Beaumont JJ, Swan SH, Hammond SK, et al. Historical cohort investigation of spontaneous abortion in the Semiconductor Health Study: epidemiologic methods and analyses of risk in fabrication overall and in fabrication work groups. Am J Ind Med 1995;28:735-50.

3 Swan SH, Beaumont JJ, Hammond SK, et al. Historical cohort study of spontaneous abortion among fabrication workers in the Semiconductor Health Study: agent-level analysis. Am J Ind Med 1995;28:751-69.

4 Eskenazi B, Gold EB, Lasley BL, et al. Prospective monitoring of early fetal loss and clinical spontaneous abortion among female semiconductor workers. Am J Ind Med 1995;28:833-46.

5 Correa A, Gray RH, Cohen R, et al. Ethylene glycol ethers and risks of spontaneous abortion and subfertility. Am J Epidemiol 1996;143:707-17.

6 Eskenazi B, Gold EB, Samuels SJ, et al. Prospective assessment of fecundability of female semiconductor workers. Am J Ind Med 1995;28:817-31.

7 Chen PC, Hsieh GY, Wang JD, et al. Prolonged time to pregnancy in female workers exposed to ethylene glycol ethers in semiconductor manufacturing. Epidemiology 2002;13:191-6.

8 Scott WJ, Fradkin R, Wittfoht W, et al. Teratologic potential of 2methoxyethanol and transplacental distribution of its metabolite, 2methoxyacetic acid, in non-human primates. Teratology 1989:39:363-73.

9 Clarke DO, Elswick BA, Welsch F, et al. Pharmacokinetics of 2methoxyethanol and 2-methoxyacetic acid in the pregnant mouse: a physiologically based mathematical model. Toxicol Appl Pharmacol 1993; 121:239-52. 
10 Davis BJ, Almekinder JL, Flagler N, et al. Ovarian luteal cell toxicity of ethylene glycol monomethyl ether and methoxy acetic acid in vivo and in vitro. Toxicol Appl Pharmacol 1997; 142:328-37.

11 Almekinder JL, Lennard DE, Walmer DK, et al. Toxicity of methoxyacetic acid in cultured human luteal cells. Fundam Appl Toxicol 1997;38:191-4.

12 Gold EB, Eskenazi B, Hammond SK, et al. Prospectively assessed menstrual cycle characteristics in female wafer-fabrication and non-fabrication semiconductor employees. Am J Ind Med 1995;28:799-815.

13 Chia SE, Foo SC, Khoo NY, et al. Menstrual patterns of workers exposed to low levels of 2-ethoxyethylacetate (EGEEA). Am J Ind Med 1997;31:148-52.

14 Hammond SK, Hines CJ, Hallock MF, et al. Tiered exposure-assessment strategy in the Semiconductor Health Study. Am J Ind Med 1995;28:661-80.

15 Cheng TA, Williams $P$. The design and development of a screening questionnaire (CHQ) for use in community studies of mental disorders in Taiwan. Psychol Med 1986;16:415-22.

16 Vollman RF. The degree of variability of the length of the menstrual cycle in correlation with age of women. Gynaecologia 1956;142:310-14.

17 Treloar AE, Boynton RE, Behn BG, et al. Variation of the human menstrual cycle through reproductive life. Int J Fertil 1970;12:77-126.

18 Chiazze L, Brayer FT, Mascico JJ, et al. The length and variability of the human menstrual cycle. JAMA 1968;203:377-80.

19 Rubinow DR, Roy-Byrne P. Premenstrual syndromes: overview from a methodologic perspective. Am J Psychiatry 1984;141:163-72.

20 Bloch M, Schmidt PJ, Rubinow DR. Premenstrual syndrome: evidence for symptom stability across cycles. Am J Psychiatry 1997;154:1741-6.

21 Thompson ML, Myers JE, Kriebel D. Prevalence odds ratio or prevalence ratio in the analysis of cross sectional data: what is to be done? Occup Environ Med 1998:55:272-7.

22 Harlow SD, Matanoski GM. The association between weight, physical activity, and stress and variation in the length of the menstrual cycle. Am J Epidemiol $1991 ; 133: 38-49$

23 Rowland AS, Baird DD, Long S, et al. Influence of medical conditions and lifestyle factors on the menstrual cycle. Epidemiology 2002;13:668-74.

24 Hornsby PP, Wilcox AJ, Weinberg CR. Cigarette smoking and disturbance of menstrual function. Epidemiology 1998;9:193-8.
25 Lohstroh PN, Chen J, Ba J, et al. Bone resorption is affected by follicular phase length in female rotating shift workers. Environ Health Perspect 2003;111:618-22.

26 Sternfeld B, Jacobs MK, Quesenberry CP Jr, et al. Physical activity and menstrual cycle characteristics in two prospective cohorts. Am J Epidemiol 2002;156:402-9

27 Aksel S. Hormonal characteristics of long cycles in fertile women. Fertil Steril $1981 ; 36: 521-3$.

28 Lenton EA, Landgren BM, Sexton L, et al. Normal variation in the length of the follicular phase of the menstrual cycle: effect of chronological age. $\mathrm{Br} J$ Obstet Gynaecol 1984;91:681-4

29 Matsumoto S, Tamada T, Konuma S. Endocrinological analysis of environmental menstrual disorders. Int J Fertil 1979;24:233-9.

30 Wang JD. Scientific hypothesis and degree of corroboration. In: Wang JD, eds. Basic principles and practical applications in epidemiological research. Singapore: World Scientific, 2002:39-55.

31 Allen B, Gentry R, Shipp A, et al. Calculation of benchmark doses for reproductive and developmental toxicity observed after exposure to isopropanol. Regul Toxicol Pharmacol 1998;28:38-44.

32 Zeleznik AJ. Premature elevation of systemic estradiol reduces serum levels of follicle-stimulating hormone and lengthens the follicular phase of the menstrual cycle in rhesus monkeys. Endocrinology 1981;109:352-5.

33 Zeleznik AJ, Hutchison JS, Schuler HM. Interference with the gonadotropinsuppressing actions of estradiol in macaques overrides the selection of a single preovulatory follicle. Endocrinology 1985;117:991-9.

34 Joffe M. Biases in research on reproduction and women's work. Int J Epidemiol 1985; 14:118-23.

35 Kesner JS, Wright DM, Schrader SM, et al. Methods of monitoring menstrual function in field studies: efficacy of methods. Reprod Toxicol 1992;6:385-400

36 Waller K, Swan SH, Windham GC, et al. Use of urine biomarkers to evaluate menstrual function in healthy premenopausal women. Am J Epidemiol 1998;147:1071-80.

37 Gold EB, Eskenazi B, Lasley BL, et al. Epidemiologic methods for prospective assessment of menstrual cycle and reproductive characteristics in female semiconductor workers. Am J Ind Med 1995;28:783-97. 